\title{
Process parameter-growth environment-film property relationships for the sputter deposited yttrium-oxygen system
}

\author{
Chee-Kin Kwok and Carolyn Rubin Aita \\ Materials Department and the Laboratory for Surface Studies, University of Wisconsin-Milwaukee, \\ Milwaukee, Wisconsin 53201 \\ Elzbieta Kolawa \\ California Institute of Technology, Pasadena, California 91125
}

(Received 31 October 1989; accepted 6 November 1989)

\begin{abstract}
In this study, a $\mathrm{Y}$ target was sputtered in radio frequency ( $\mathrm{rf}$ )-excited, rare gas discharges ( $\mathrm{Ne}$, Ar) containing $0 \%-40 \% \mathrm{O}_{2}$, operated at cathode voltage from -1.0 to $-1.7 \mathrm{kV}$. In situ optical emission spectrometry was used to monitor two neutral excited $\mathrm{Y}$ atom transitions $(\lambda=0.6191$, $0.6793 \mu \mathrm{m})$ and an excited $O$ atom transition $(\lambda=0.7774 \mu \mathrm{m})$ as a function of changing process parameter. Films were grown on fused $\mathrm{SiO}_{2}$ substrates, and their crystallography, optical behavior, and electrical resistivity was determined. A "phase diagram" for Y-O not grown under conditions of equilibrium thermodynamics was constructed, and included hexagonal $Y$, cubic $\mathrm{Y}_{2} \mathrm{O}_{3}$, and $\mathrm{Y}$ and $\mathrm{Y}_{2} \mathrm{O}_{3}$ that had no long range crystallographic order. Two direct optical transitions across the energy band gap of cubic $\mathrm{Y}_{2} \mathrm{O}_{3}$, at 5.07 and $5.73 \mathrm{eV}$, were identified. Combining discharge diagnostics, growth rate, and film property results, it was concluded that $\mathrm{Y}_{2} \mathrm{O}_{3}$ was formed at the substrate concurrent with the complete oxidation of the target surface. Even after target oxidation, the discharge contained atomic $Y$. On the basis of fundamental optical absorption edge characteristics, cubic $\mathrm{Y}_{2} \mathrm{O}_{3}$ that more closely resembled the bulk material was obtained when the $Y$-oxide molecule/ $Y$ atom flux to the substrate was high.
\end{abstract}

\section{INTRODUCTION}

The purpose of this study is to investigate process parametergrowth environment-film property relationships for the reactive sputter deposited $\mathrm{Y}-\mathrm{O}$ materials system. Films were prepared by sputtering a $\mathrm{Y}$ target using $\mathrm{O}_{2}$-bearing discharges. The transition from $\mathrm{Y}$ to $\mathrm{Y}_{2} \mathrm{O}_{3}$ growth was studied as a function of three process parameters: (1) the cathode voltage, (2) the $\mathrm{O}_{2}$ content of the sputtering gas, and (3) the type of rare gas used in conjunction with $\mathrm{O}_{2}$. These parameters can be independently varied, and combined, they determine other important parameters such as discharge power and growth rate.

The experimental program included optical emission spectrometry for in situ discharge diagnostics. Two optical transitions of the neutral $Y$ atom from a low-lying excited state to the ground state were used to monitor the $Y$ atomic population in the discharge as a function of changing process parameter. In addition, an optical transition of the neutral $O$ atom was used to monitor target surface oxidation. The film properties that were investigated are crystallography, visible-near-ultraviolet optical behavior, and electrical resistivity.

Thin film yttria is of interest as a capacitor material and although there have been only a few reports of its fabrication, these reports cover a wide variety of techniques including post-deposition oxidation of $\mathrm{Y}$ films, ${ }^{1,2}$ physical vapor and inductively coupled plasma deposition using a $\mathrm{Y}_{2} \mathrm{O}_{3}$ powder source, ${ }^{3-6}$ and $\mathrm{rf}$ - and ion-beam sputter deposition from a $\mathrm{Y}_{2} \mathrm{O}_{3}$ target. ${ }^{7,8}$ Reactive sputter deposition using a metal target and an $\mathrm{O}_{2}$-bearing discharge is an important method for near room temperature metal-oxide film growth. We hope that the results presented below will enable other inves- tigators to reproducibly grow yttria films with desired properties by this method.

\section{EXPERIMENTAL PROCEDURE}

Films were grown in a radio frequency (rf) diode sputter deposition apparatus. A $13 \mathrm{~cm}$ diameter $99.8 \% \mathrm{Y}$ target was thermally bonded to a water-cooled $\mathrm{Cu}$ cathode. Supersil fused silica substrates were placed on a water-cooled $Y$-coated $\mathrm{Cu}$ pallet covering the anode. The anode-cathode spacing was $7 \mathrm{~cm}$.

The chamber was evacuated to $<5 \times 10^{-7}$ Torr with a liquid $\mathrm{N}_{2}$-trapped, hot Si-base oil diffusion pump and backfilled with the sputtering gas to a total pressure of $1 \times 10^{2}$ Torr. The sputtering gas consisted of a rare gas, $\mathrm{Ne}$ (99.996\%) or $\operatorname{Ar}(99.999 \%)$, containing from $0 \%$ to $40 \%$ $\mathrm{O}_{2}(99.99 \%)$. Each component was separately admitted into the chamber using an MKS Instruments Baratron Series 260 pressure/flow control system.

Two presputters preceded each deposition. The first presputter was carried out in pure rare gas for $30 \mathrm{~min}$, and its purpose was to remove the oxide layer that had formed on the target surface upon exposure to air. The second presputter was carried out in the rare gas- $\mathrm{O}_{2}$ mixture used to deposit the film and its purpose was to allow time for discharge and target surface reactions to reach dynamic equilibrium. The movable shutter that covered the substrates was then removed and the films were deposited according to the conditions listed in Table I. Values of cathode voltage from -1.0 to $-1.7 \mathrm{kV}$ peak-to-peak were used. The anode was kept at ground potential.

A model HR320 Instruments SA optical spectrometer with 1200 and 2400 groove/ $\mathrm{mm}$ holographic gratings capa- 
TABLE I. Deposition parameters, film thickness, growth rate, and resistivity of $\mathrm{Y}$ and $\mathrm{Y}_{2} \mathrm{O}_{3}$ films sputter deposited on fused $\mathrm{SiO}_{2}$.

\begin{tabular}{|c|c|c|c|c|c|c|c|}
\hline Fim & $\begin{array}{l}\text { Rare } \\
\text { gas }\end{array}$ & $\% \mathrm{O}_{2}$ & $\begin{array}{c}V_{c} \\
(-k V)\end{array}$ & $\begin{array}{l}\text { Power } \\
\text { (W) }\end{array}$ & $\begin{array}{c}x \\
\left(10^{2} \mathrm{~nm}\right)\end{array}$ & $\begin{array}{c}G \\
(\mathrm{~nm} / \mathrm{min})\end{array}$ & $\begin{array}{c}\rho^{\mathrm{a}} \\
(\mu l \mathrm{~cm})\end{array}$ \\
\hline 1 & Ar & 0 & 1.7 & 310 & $25.7+0.7$ & $32.0 \pm 0.9$ & $254 \pm 19$ \\
\hline 2 & $\mathrm{Ar}$ & 2 & 1.7 & 340 & $24.2 \pm 0.6$ & $28.4+0.7$ & $2411+74$ \\
\hline 3 & $\mathrm{Ar}$ & 4 & 1.7 & 670 & $4.9+0.6$ & $5.3 \div 0.7$ & nc \\
\hline 4 & Ar & 0 & 1.5 & 280 & $6.5 \pm 0.3$ & $28.4 \pm 1.2$ & $196+13$ \\
\hline 5 & Ar & 2 & 1.5 & 350 & $12.0 \pm 0.4$ & $28.6 \pm 0.9$ & $364 \pm 44$ \\
\hline 6 & Arr & 4 & 1.5 & 600 & $3.3+0.2$ & $5.0 \pm 0.3$ & ne \\
\hline 7 & $\mathrm{Ar}$ & 20 & 1.5 & 620 & $1.7 \pm 0.1$ & $4.5 \pm 0.3$ & $\mathrm{nc}$ \\
\hline 8 & $\mathrm{Ar}$ & 0 & 1.3 & 170 & $5.5 \pm 0.1$ & $21.1 \pm 0.5$ & $200+8$ \\
\hline 9 & Ar & 2 & 1.3 & 390 & $2.2 \pm 0.2$ & $4.2 \pm 0.4$ & nc \\
\hline 10 & Ar & 20 & 1.3 & 400 & $1.9 \pm 0.2$ & $3.2+0.3$ & ne \\
\hline 11 & Ar & 40 & 1.3 & 400 & $2.4 \pm 0.2$ & $2.8+0.3$ & nc \\
\hline 12 & Re & 0 & 1.7 & 360 & $12.2+0.7$ & $10.1 \pm 0.6$ & $248 \pm 22$ \\
\hline 13 & $\mathrm{Ne}$ & 2 & 1.7 & 450 & $1.4 \pm 0.2$ & $2.0 \pm 0.3$ & ne \\
\hline 14 & $\mathrm{Ne}$ & 4 & 1.7 & 460 & $1.6 \pm 0.1$ & $1.8+0.1$ & ne \\
\hline 15 & $\mathrm{Ne}$ & 20 & 1.7 & 630 & $1.7 \pm 0.1$ & $2.2 \pm 0.1$ & ne \\
\hline 16 & $\mathrm{Ne}$ & 0 & 1.5 & 290 & $5.9 \pm 0.4$ & $7.4+0.5$ & $193+19$ \\
\hline 17 & $\mathrm{Ne}$ & 2 & 1.5 & 405 & $1.2+0.1$ & $2.0 \pm 0.1$ & ne \\
\hline 18 & $\mathrm{Ne}$ & 4 & 1.5 & 405 & $2.1 \pm 0.4$ & $2.3+0.5$ & ne \\
\hline 19 & $\mathrm{Ne}$ & 20 & 1.5 & 450 & $1.2 \pm 0.1$ & $2.0 \pm 0.2$ & ne \\
\hline 20 & $\mathrm{Ne}$ & 40 & 1.5 & 580 & $1.8 \pm 0.1$ & $2.2 \pm 0.2$ & $n c$ \\
\hline 21 & $\mathrm{Ne}$ & 0 & 1.3 & 180 & $1.9 \pm 0.2$ & $9.3+0.1$ & $503+40$ \\
\hline 22 & $\mathrm{Ne}$ & 2 & 1.3 & 270 & $1.0+0.3$ & $1.7+0.5$ & ne \\
\hline 23 & $\mathrm{Ne}_{\mathrm{e}}$ & 20 & 1.3 & 330 & $1.1 \pm 0.1$ & $1.8 \pm 0.2$ & $\mathrm{ne}$ \\
\hline 24 & $\mathrm{Ne}$ & 40 & 1.3 & 430 & $1.5+0.2$ & $2.4+0.3$ & ne \\
\hline 25 & $\mathrm{Ne}$ & 20 & 1.0 & 170 & $1.4 \pm 0.2$ & $1.2 \pm 0.2$ & ne \\
\hline 26 & $\mathrm{Ne}$ & 40) & 1.0 & 190 & $1.4+0.2$ & $1.2 \pm 0.2$ & nc \\
\hline
\end{tabular}

" $\rho$ for buik $Y=57 \mu \Omega \mathrm{cm}$.

ble of $0.05 \mathrm{~nm}$ resolution was used for in situ optical emission diagnostics of the discharge. Radiation emitted from the region between the anode and cathode was sampled as a function of wavelength through an optical window with a transmission cutoff of $0.32 \mu \mathrm{m}$. The window was shuttered when not in use, and was also periodically removed from the chamber and its transmission characteristics were checked by spectrophotometry to monitor and correct for intensity changes caused by coating with sputtered flux in the course of the experiment.

The emission intensity $I\left(\mathrm{Y}^{*}\right)$ from two optical transitions of the neutral $Y$ atom, at $\lambda=0.6191$ and $0.6793 \mu \mathrm{m},{ }^{19}$ was monitored. The lower level of the transitions is the $Y$ atom ground state $Y^{0}$. The glow discharges studied here are not in thermal equilibrium. Therefore, the number of atoms at the upper and lower levels of the transition, $n\left(\mathrm{Y}^{*}\right)$ and $n\left(\mathrm{Y}^{0}\right)$ respectively, are not directly related through the statistical weight of each level and the Boltzmann factor. However, if the discharge is optically thin, ${ }^{10}$ changes in $n\left(\mathrm{Y}^{*}\right)$ are directly proportional to changes in $I\left(\mathrm{Y}^{*}\right)$ and can be used to estimate changes in $n\left(\mathrm{Y}^{0}\right) .{ }^{11}$ Emission from neutral atomic $\mathrm{O}, \lambda=0.7774 \mu \mathrm{m}$, was used to detect the presence of oxygen in the discharge. ${ }^{12}$

Film thickness $x$ was measured postdeposition with a Tencor Alpha-Step 200 model profilometer. The growth rate, $G$, was determined from this measurement. Electrical resistivity $\rho$ was measured using a four-point probe. Crystallography was determined by double-angle $\mathrm{X}$-ray diffraction (XRD) using $\mathrm{Cu} K \alpha$ radiation $(\lambda=0.15418 \mathrm{~nm})$. Peak position $(2 \theta)$, relative intensity, and full widh at one-half of the maximum intensity (FWHM) were determined. The diffractometer was calibrated using the (01.1) diffraction peak of a quartz standard at $2 \theta=26.66 \pm 0.02^{\circ}$, whose width is $0.18^{\circ}$. Rutherford backscattering spectroscopy (RBS) was carried out on selected films to determine the relative atomic concentration of $Y$ and $O .2 \mathrm{MeV} \mathrm{He}^{+2}$ ions were used as the bombarding species.

A Perkin-Elmer Model 330 UV-visible-IR double beam spectrophotometer with a specular refiection attachment was used to determine the transmittance $T$ and reflectance $R$ of near-normal incident radiation. Measurements were made in laboratory air at room temperature. The absorption coefficient $\alpha$ was calculated from ${ }^{13}$

$$
T=\left[(1-R)^{2} \exp (-\alpha x)\right] /\left[1-R^{2} \exp (-2 \alpha x)\right] .
$$

\section{RESULTS AND DISCUSSION}

Film thickness, growth rate, and resistivity are recorded in Table I. Crystallographic parameters are recorded in Table II. Films grown in Ar-O, discharges show two phases, hexagonal close-packed $\mathrm{Y}$ and body-centered-cubic $\mathrm{Y}_{2} \mathrm{O}_{3}$. There are two additional structures present in films grown in $\mathrm{Ne}-\mathrm{O}_{2}$ discharges, metallic (Film No. 21) and insulating (Film Nos. 22, 25, and 26) phases that have no long range crystallographic order detectable by XRD. RBS results show that the nonmetallic phase is chemically identifiable as $\mathrm{Y}_{2} \mathrm{O}_{3}$, and is denoted here as " $\alpha-\mathrm{Y}_{2} \mathrm{O}_{3}$." Figure 1 shows the 
TABI.E II. Major diffraction planes in $\mathrm{Y}$ and $\mathrm{Y}_{2} \mathrm{O}_{3}$ films

\begin{tabular}{|c|c|c|c|c|c|}
\hline Film & $2 \theta(\mathrm{deg})$ & Plane & FWHM (deg) & Rel. I & $d_{l k i}(\mathrm{~nm})^{\mathrm{a}}$ \\
\hline \multirow[t]{2}{*}{1} & 30.92 & $00.2 \alpha-\mathrm{Y}$ & 0.46 & 100 & 0.289 \\
\hline & 64.49 & $00.4 \alpha-Y$ & 0.93 & 3 & 0.145 \\
\hline \multirow[t]{2}{*}{2} & 30.86 & $00.2 \alpha=Y$ & 0.42 & 100 & 0.290 \\
\hline & 64.32 & $00.4 \alpha-\mathrm{Y}$ & 0.76 & 3 & 0.145 \\
\hline \multirow[t]{2}{*}{3} & 29.02 & $222 \mathrm{c}-\mathrm{Y}_{2} \mathrm{O}_{3}$ & 0.70 & 100 & 0.308 \\
\hline & 48.14 & $440 c-Y_{2} O_{3}$ & 1.10 & 21 & 0.189 \\
\hline \multirow[t]{2}{*}{4} & 30.96 & $00.2 a+Y$ & 0.38 & 100 & 0.289 \\
\hline & 64.49 & $00.4 \alpha-Y$ & 0.82 & 2 & 0.145 \\
\hline \multirow[t]{2}{*}{5} & 30.81 & $00.2 \alpha-Y$ & 0.46 & 100 & 0.290 \\
\hline & 64.11 & $00.4 \alpha-\mathrm{Y}$ & 0.50 & 2 & 0.145 \\
\hline 6 & 29.01 & $222 c-\mathrm{Y}_{2} \mathrm{O}_{3}$ & 0.76 & 100 & 0.308 \\
\hline 7 & 28.94 & $222 \mathrm{c}-\mathrm{Y}_{2} \mathrm{O}_{3}$ & 0.68 & 100 & 0.309 \\
\hline 8 & 30.96 & $00.2 \alpha-\mathrm{Y}$ & 0.38 & 100 & 0.289 \\
\hline 9 & 28.98 & $222 c-\mathrm{Y}_{2} \mathrm{O}_{3}$ & 0.78 & 100 & 0.308 \\
\hline 10 & 28.97 & $222 c-Y_{2} O_{3}$ & 0.77 & 100 & 0.308 \\
\hline 11 & 28.96 & $222 \mathrm{c}-\mathrm{Y}_{2} \mathrm{O}_{3}$ & 0.80 & 100 & 0.308 \\
\hline \multirow[t]{4}{*}{12} & 27.89 & $10.0 \alpha-Y$ & 0.42 & 32 & 0.320 \\
\hline & 30.44 & $00.2 \alpha-\mathrm{Y}$ & 0.64 & 10 & 0.294 \\
\hline & 31.95 & $10.1 \alpha-Y$ & 0.59 & 6 & 0.280 \\
\hline & 49.16 & $11.0 \alpha-Y$ & 0.64 & 100 & 0.185 \\
\hline 13 & 28.96 & $222 \mathrm{c}-\mathrm{Y}_{2} \mathrm{O}_{3}$ & 0.82 & 100 & 0.308 \\
\hline 14 & 28.93 & $222 \mathrm{c} \cdot \mathrm{Y}_{2} \mathrm{O}_{3}$ & 0.78 & 100 & 0.309 \\
\hline 15 & 28.94 & $222 c-Y_{2} O_{3}$ & 0.71 & 100 & 0.309 \\
\hline \multirow[t]{4}{*}{16} & 49.09 & $11.0 \alpha-\mathrm{Y}$ & 0.62 & 100 & 0.186 \\
\hline & 27.86 & $10.0 \alpha-Y$ & 0.41 & 26 & 0.320 \\
\hline & 30.38 & $00.2 \alpha-Y$ & 0.60 & 6 & 0.294 \\
\hline & 31.88 & $10.1 \alpha \cdot Y$ & 0.63 & 21 & 0.281 \\
\hline 17 & 28.95 & $222 \mathrm{c}-\mathrm{Y}_{2} \mathrm{O}_{3}$ & 0.83 & 100 & 0.308 \\
\hline 18 & 28.97 & $222 c-Y_{2} \mathrm{O}_{3}$ & 0.75 & 100 & 0.308 \\
\hline 19 & 28.97 & $222 c-Y_{2} O_{3}$ & 0.75 & 100 & 0.308 \\
\hline 20 & 28.89 & $222 c=Y_{2} O_{3}$ & 0.67 & 100 & 0.309 \\
\hline 21 & no diffraction peaks & & & & \\
\hline 22 & no diffraction peaks & & & & \\
\hline 23 & 28.94 & $222 c-\mathrm{Y}_{2} \mathrm{O}_{3}$ & 0.83 & 100 & 0.309 \\
\hline 24 & 28.96 & $222 \mathrm{c}-\mathrm{Y}_{2} \mathrm{O}_{3}$ & 0.77 & 100 & 0.308 \\
\hline 25 & no diffraction peaks & & & & \\
\hline 26 & no diffraction peaks & & & & \\
\hline
\end{tabular}

" $d_{h k l}$ for bulk unstressed material (in nm): hexagonal $\alpha$-Y (10.0)-0.315, (00.2)-0.286, (10.1)-0.280, (11.0)-0.182; cubic c-Y $\mathrm{Y}_{2} \mathrm{O}_{3}(222)-0.306,(440)-$ 0.187 .

fields over which all phases exist as a function of cathode voltage and gas $\mathrm{O}_{2}$ content for (a) $\mathrm{Ar}-\mathrm{O}_{2}$ and (b) $\mathrm{Ne}-\mathrm{O}_{2}$ discharges.

In terms of visual appearance, all $\mathrm{Y}_{2} \mathrm{O}_{3}$ films are transparent and colorless. Figure 2 shows the optical absorption coefficient calculated from Eq. (1) as a function of incident photon energy, $E$, for two films that represent the extremes in yttria optical behavior observed here: Film No. 7, which is $c-\mathrm{Y}_{2} \mathrm{O}_{3}$, and Film No. 22, which is $a-\mathrm{Y}_{2} \mathrm{O}_{3}$. Two optical transitions across the energy band gap occur in Film No. 7. There is a direct dependence of $\alpha^{2}$ on $E$ for both transitions, as shown in Fig. 3, indicating direct transitions. ${ }^{13}$ Extrapolation of the data in Fig. 3 to $\alpha=0$ yields $E_{g 1}=5.07 \mathrm{eV}$ and $E_{g 2}=5.73 \mathrm{eV}$. Two optical absorption studies of single crystal $\mathrm{Y}_{2} \mathrm{O}_{3}$ place the band gap at $\sim 5.6 \mathrm{eV}^{14}$ and $\sim 6.1 \mathrm{eV},{ }^{15}$ measured from the short wavelength limit of transmission. The value of $E_{\mathrm{g} 2}$ obtained here is in good agreement with the single crystal values.

It can be seen from Fig. 2 that the $\alpha$ versus $E$ data for Film No. 22 lacks the fine structure present in Film No. 7. How- ever, a change of slope in the curve for Film No. 22 occurs in the vicinity of the onset of the higher energy transition in Film No. 7. At high photon energy, the curves for Film Nos. 7 and 22 converge indicating similar $\mathrm{Y}-\mathrm{O}$ short range order.

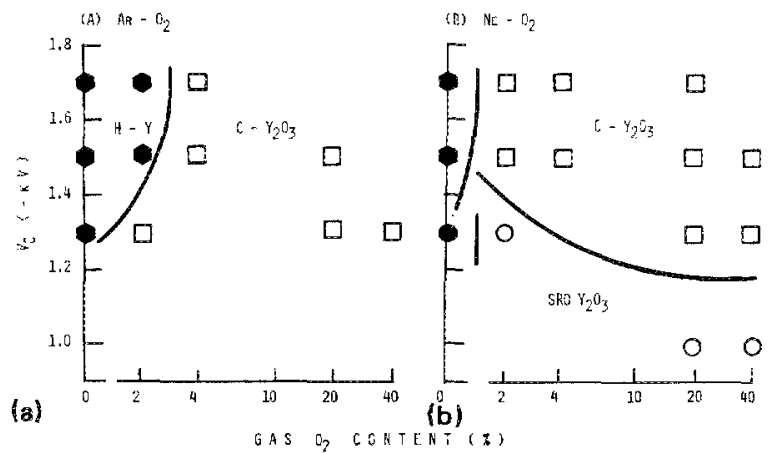

FIG. 1. A "phase diagram" for sputter deposited $\mathrm{Y}-\mathrm{O}$ films. The crystal structure as a function of the cathode voltage and gas $\mathrm{O}_{2}$ content.

hexagonal $\mathrm{Y},-$ short range order $\mathrm{Y}, \mathrm{Q}-$ cubic $\mathrm{Y}_{2} \mathrm{O}_{3}, \mathrm{O}$-short range order $\mathrm{Y}_{2} \mathrm{O}_{3}$. (a) Ar $-\mathrm{O}_{2}$ and (b) $\mathrm{Ne}-\mathrm{O}_{2}$. 


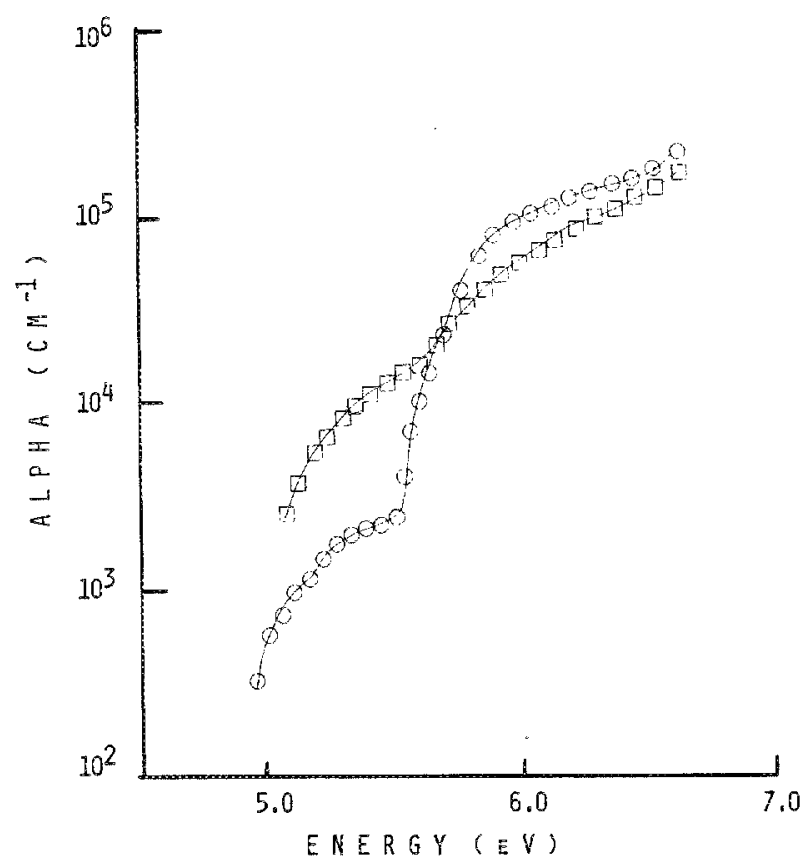

FIG. 2. The optical absorption coefficient as a function of the incident photon energy for $t w o$ representative films: $\mathrm{O}-c-\mathrm{Y}_{2} \mathrm{O}_{3}, \square-a-\mathrm{Y}_{2} \mathrm{O}_{3}$.

The fundamental optical absorption edges of $c-\mathrm{Y}_{2} \mathrm{O}_{3}$ Film Nos. 10, 11, and 20 are coincident with that of Film No. 7 . The edges of $a-Y_{2} O_{3}$ Film Nos. 25 and 26 are coincident with that of Film No. 22. However, all other $c-\mathrm{Y}_{2} \mathrm{O}_{3}$ films have edges whose features are less sharp than those of Film No. 7, indicating a greater amount of disorder, and yet not as featureless as the edge of Film No. 22. We will relate this phenomenon to the growth environment below.

With respect to discharge characteristics, the optical emission intensity from $\mathrm{Y}^{*}$ atoms is recorded in Table III. All values are relative to the intensity of the transition in a pure rare gas discharge operated at the same cathode voltage. There apparently is a resonance between the $Y$ transition at $0.6191 \mu \mathrm{m}(2.006 \mathrm{eV})$ and a strong $\mathrm{O}$ transition at $0.6157 \mu \mathrm{m}(2.017 \mathrm{eV})$ that enhances $I\left(\mathrm{Y}_{0.6191}^{*}\right)$ in $\mathrm{Ne}-\mathrm{O}_{2}$ discharges under some conditions, as indicated in Table III, and these data are not representative of a change $n\left(\mathrm{Y}^{\circ}\right)$.

The relative arrival rate $A$ is also included in Table III. This quantity is the growth rate relative to its value in a pure rare gas discharge operated at the same cathode voltage corrected for the difference in density between $Y\left(4.47 \mathrm{~g} / \mathrm{cm}^{3}\right)$ and $\mathrm{Y}_{2} \mathrm{O}_{3}\left(5.01 \mathrm{~g} / \mathrm{cm}^{3}\right)$ when applicable. Bulk values for density are used here. It is well known that the metal target surface reacts with oxygen during reactive sputtering and the sputtered flux will consist of both metal and metal-oxide species. The relative arrival rate is assumed here to be proportional to the fiux of $Y$ to the substrate both in atomic form and bonded to $\mathrm{O}$ in a gaseous $\mathrm{Y}$-oxide molecule of unknown chemistry.

Using a comparison of $I\left(\mathrm{Y}^{*}\right)$ and $A$ in $\mathrm{Ar}-\mathrm{O}_{2}$ discharges operated at -1.5 and $-1.7 \mathrm{kV}$ as an exampie, we can define three types of behavior as the sputtering gas $\mathrm{O}_{2}$ content is increased. Type I: $I\left(\mathrm{Y}^{*}\right)$ decreases faster than $A$ as $2 \% \mathrm{O}_{2}$ is added to the discharge, indicating that some form of $\mathrm{Y}-$ oxide is being formed at and sputtered from the target surface as a molecule, along with atomic $Y$. Films grown under

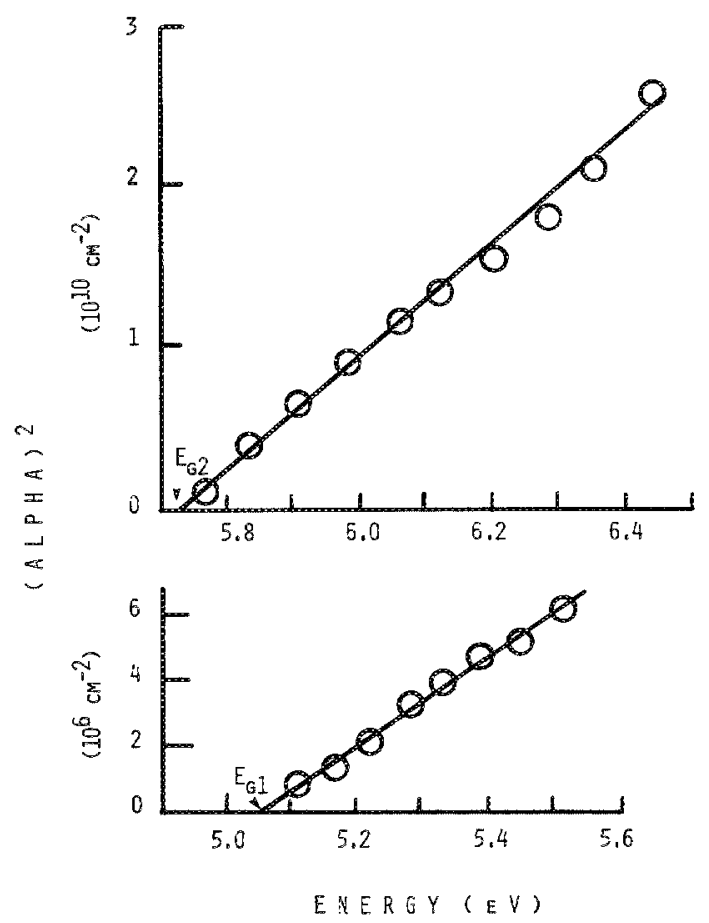

Fic. 3. The square of the absorption coefficient as a function of the incident photon energy for $c-Y_{2} \mathrm{O}_{3}$. Extrapolation of the data to $\alpha^{2}=0$ yields $E_{1 g}=5.07 \mathrm{eV}$ and $E_{2 g}=5.73 \mathrm{eV}$ for two direct transitions across the energy band gap.

these conditions are metallic but have a resistivity that is higher than that of films grown in pure rare gas operated at the same cathode voltage, suggesting the incorporation of $O$. Type II: Both $I\left(\mathrm{Y}^{*}\right)$ and $A$ decrease to $\sim 20 \%$ of their value in pure rare gas as the gas $\mathrm{O}_{2}$ content is increased to $4 \%$. Concurrently, (1) an emission line at $0.7774 \mu \mathrm{m}$ signals the presence of $O$ in the discharge, and (2) the discharge power nearly doubles. $O$ in the discharge indicates that the target is no longer gettering oxygen. $\mathrm{Y}_{2} \mathrm{O}_{3}$ is a better electron emitter than $Y$, and the increase in discharge power indicates that a complete oxide layer has formed at the target surface. Films grown under these conditions are $c-Y_{2} \mathrm{O}_{3}$, but have a fundamental optical absorption edge that lacks the sharpness of the representative curve for $c-Y_{2} \mathrm{O}_{3}$ shown in Fig. 2. Type III: $I\left(\mathrm{Y}^{*}\right)$ decreases further and $A$ remains constant as the gas $\mathrm{O}_{2}$ content is increased to $20 \%$, indicating that there is a larger flux of $Y$ arriving at the substrate in a form other than atomic $Y$, compared to Type II. Type III behavior is earmarked by a value of $I\left(\mathrm{Y}^{*}\right)$ that is less than $A$. The resulting films are $c-\mathrm{Y}_{2} \mathrm{O}_{3}$, with an optical absorption edge represented by the curve shown for $c-Y_{2} \mathrm{O}_{3}$ in Fig. 2 .

Type III behavior occurs in $\mathrm{Ar}-\mathrm{O}_{2}$ discharges containing $\geqslant 2 \% \mathrm{O}_{2}$ operated at $-1.3 \mathrm{kV}$, and in $\mathrm{Ne}-40 \% \mathrm{O}_{2}$ operated at $-1.5 \mathrm{kV}$. Type II behavior occurs in $\mathrm{Ne}-\mathrm{O}_{2}$ discharges operated at all values of $V_{c}$ for gas $\mathrm{O}_{2}$ content between 2 and $20 \% \mathrm{O}_{2}$. Type II behavior represents a relatively large metal flux associated with an oxidized target surface, which can come about either by dissociation of the $\mathrm{Y}$-oxide at the target surface upon sputtering, or by dissociation of the sputtered gaseous $\mathrm{Y}$-oxide molecule in the negative glow. With respect to process parameters, high cathode voltage, low gas 
TABLE III. Relative intensity of $\mathrm{Y}$ optical emission transitions monitored in Ar $-\mathrm{O}_{2}$ and $\mathrm{Ne}-\mathrm{O}_{2}$ discharges during $\mathrm{Y}$ and $\mathrm{Y}_{2} \mathrm{O}_{3}$ film growth, and the relative $\mathrm{Y}$ arrival rate.

\begin{tabular}{|c|c|c|c|c|c|}
\hline Rare gas & $\% \mathrm{O}_{2}$ & $V(\cdots \mathrm{kV})$ & $I(0.6191 \mu \mathrm{m})$ & $I(0.6793 \mu \mathrm{m})$ & $A$ \\
\hline $\mathrm{Ar}$ & 0 & 1.7 & 100 & 100 & 100 \\
\hline Ar & 2 & 1.7 & 70 & 70 & 89 \\
\hline $\mathrm{Ar}$ & 4 & 1.7 & 19 & 12 & 15 \\
\hline Ar & 0 & 1.5 & 100 & 100 & 100 \\
\hline $\mathrm{Ar}$ & 2 & 1.5 & 60 & 60 & 100 \\
\hline $\mathrm{Ar}$ & 4 & 1.5 & 15 & 15 & 16 \\
\hline Ar & 20 & 1.5 & 3 & 2 & 14 \\
\hline Ar & 0 & 1.3 & 100 & 100 & 100 \\
\hline $\mathrm{Ar}$ & 2 & 1.3 & 6 & 5 & 18 \\
\hline Ar & 20 & 1.3 & 7 & 4 & 13 \\
\hline $\mathrm{Ar}$ & 40 & 1.3 & 7 & 3 & 12 \\
\hline $\mathrm{Ne}$ & 0 & 1.7 & 100 & 100 & 100 \\
\hline $\mathrm{Ne}$ & 2 & 1.7 & 59 & 52 & 18 \\
\hline $\mathrm{Ne}$ & 4 & 1.7 & 38 & 38 & 16 \\
\hline $\mathrm{Ne}$ & 20 & 1.7 & $53^{h}$ & 31 & 19 \\
\hline $\mathrm{Ne}$ & 0 & 1.5 & 100 & 100 & 100 \\
\hline $\mathrm{Ne}$ & 2 & 1.5 & 62 & 65 & 24 \\
\hline $\mathrm{Ne}$ & 4 & 1.5 & 66 & 60 & 27 \\
\hline $\mathrm{Ne}$ & 20 & 1.5 & $85^{b}$ & 25 & 24 \\
\hline $\mathrm{Ne}$ & 40 & 1.5 & $226^{11}$ & 20 & 26 \\
\hline $\mathrm{Ne}$ & 0 & 1.3 & 100 & 100 & 100 \\
\hline $\mathrm{Ne}$ & 2 & 1.3 & $110^{h}$ & 100 & 16 \\
\hline $\mathrm{Ne}$ & 4 & 1.3 & $113^{\mathrm{b}}$ & 83 & $\ldots$ \\
\hline $\mathrm{Ne}$ & 20 & 1.3 & $114^{b}$ & 26 & 17 \\
\hline
\end{tabular}

"Relative to the value in a pure rare gas discharge operated at the same value of $V_{c}$.

${ }^{b} \mathrm{Value}$ is enhanced by resonance with a strong $O$ transition at $0.6157 \mu \mathrm{m}$, and not representative of changes in $n\left(Y^{\circ}\right)$.

$\mathrm{O}_{2}$ content, and Ne rather than $\mathrm{Ar}$ as the rare gas component encourages Type II behavior. The latter result is in contrast to findings for the $\mathrm{Zr} \sim \mathrm{O}$ system, ${ }^{16}$ in which the use of Ne reduced the metal/metal oxide flux in the negative glow. Clearly, $\mathrm{Ne}$ is acting upon oxidized $\mathrm{Y}$ either at the target surface or in the negative glow in a much different way than it acts upon oxidized $\mathrm{Zr}$. This interesting phenomenon will be an area for future research.

\section{SUMMARY}

Reactive sputter deposition of $\mathrm{Y}$ and $\mathrm{Y}_{2} \mathrm{O}_{3}$ films using a $\mathrm{Y}$ target and $\mathrm{O}_{2}$-bearing discharges was studied as a function of three process parameters: cathode voltage, discharge $\mathrm{O}_{2}$ content, and type of rare gas used in conjunction with $\mathrm{O}_{2}$. In situ optical emission spectrometry was used to monitor changes in the $\mathrm{Y}$ and $\mathrm{O}$ atomic population in the negative glow as a function of changing process parameter. The range of parameters over which hexagonal $\mathrm{Y}$, cubic $\mathrm{Y}_{2} \mathrm{O}_{3}$, and $\mathrm{Y}$ and $\mathrm{Y}_{2} \mathrm{O}_{3}$ structures with no long range crystallographic order were deposited was determined. Two direct optical transitions across the energy band gap of $c-\mathrm{Y}_{2} \mathrm{O}_{3}$, at 5.07 and $5.73 \mathrm{eV}$, were identified. Combining discharge diagnostics, growth rate, and film property results, it was concluded that $\mathrm{Y}_{2} \mathrm{O}_{3}$ was formed at the substrate concurreni with the complete oxidation of the target surface. Furthermore, based on fundamental optical absorption edge characteristics, $c-\mathrm{Y}_{2} \mathrm{O}_{3}$ that more closely resembled the bulk material was obtained when the $\mathrm{Y}$-oxide/Y flux to the substrate was high.

\section{ACKNOWLEDGMENTS}

This work was supported under US ARO Grant No. DAAL03-89-K-0022 and through a gift by Johnson Controls, Inc. to the Wisconsin Distinguished Professorship of CRA.

${ }^{1}$ J. R. Rairden, J. Electrochem. Soc. 114, 75 (1966).

${ }^{2}$ M. Gurvitch, L. Manchanda, and J. M. Gibson, Appl. Phys. Lett. 51, 919 (1987).

${ }^{3}$ T. Tsutsumi, Jpn. J. Appl. Phys. 9, 735 (1970).

${ }^{4}$ D. F. Bezuidenhout and R. Pretorius, Thin Solid Films 139, 121 (1986).

${ }^{5}$ M. Sayer, M. S. Martin, and N. J. Hellicar, Thin Solid Films 6, R61 (1970).

${ }^{6}$ B. D. Merkie, R. N. Kniseley, and F. A. Schmidt, J. Appl. Phys. 62, 1017 (1987).

"R. M. Goldstein and S. C. Wigginton, Thin Solid Films 3, R41, (1969).

${ }^{8}$ R. W. Tustison, T. E. Varitimos, D. G. Montanari, and J. M. Wahl, J, Vac. Sci. Technol. A 7, 2256 (1989).

${ }^{9}$ A. N. Zaidel, Y. K. Prokofev, S. M. Kaiskii, V. A. Slavnyi, and E. Ya. Shreider, Tables of Spectral Lines (Plenum, New York, 1970).

${ }^{10}$ H. G. Kuhn, Atomic Spectra (Academic, New York, 1963), p. 80.

"J. E. Greene, J. Vac. Sci. Technol. 15, 1718 (1978).

${ }^{12}$ C. R. Aita and M. E. Marhic, J. Appl. Phys. 52, 1807 (1981); J. Vac. Sci. Technol. A 1, 69 (1983).

${ }^{13}$ See, for example, J. 1. Pankove, Optical Processes in Semiconductors (Prentice-Hall, Englewood Cliffs, NJ, 1971).

${ }^{14}$ Y. Nigara, Jpn. J. Appl. Phys. 7, 404 (1968).

${ }^{15}$ V. N. Abramov and A. I. Kuznetsov, Soc. Phys. Solid State 20, 399 (1978).

${ }^{16}$ C. - K. Kwok and C. R. Aita, J. Vac. Sci. Techno1. A 7, 1235 (1989). 